\title{
Hands-on Making Leather Goods: Learning from YouTube Videos
}

\author{
Chih-Mei Wang, Jian-Hong Ye, and Jhen-Ni Ye
}

\begin{abstract}
YouTube is the world's most popular video platform, which not only provides entertainment videos, but also allows many professional or amateur teachers to upload teaching videos for users to learn specific skills. However, most of the current research focuses on the effectiveness of YouTube for formal learning. In the perspective of cognitive-affective theory of learning with media (CATLM), the informal learning model through YouTube can also be regarded as a meaningful learning method. Therefore, based on CATLM, this research constructed a research model and proposed 4 research hypotheses. For the purpose of the research, this research used Facebook's hand-made leather goods club to distribute questionnaires, collected 258 questionnaires, and deleted a total of 51 copies of questionnaires with invalid data. Then the number of questionnaires with valid data were 207 , and the effective recovery rate was $80.2 \%$. The data were analyzed for reliability and validity, and SEM was used to verify the research model. The research results showed that: 1) YouTube self-efficacy was positively related to learning interest; 2) YouTube self-efficacy was positively related to learning attitude; 3) Learning attitude was positively related to $h$ learning satisfaction; 4) Learning interest was positively related to learning satisfaction.
\end{abstract}

Index Terms-Hand-made leather goods, learning attitude, learning satisfaction, self-efficacy, YouTube.

\section{INTRODUCTION}

With the development of information technology, YouTube has become a promising step-by-step learning channel [1], and it provides many convenient functions, such as pause, full-screen window, or fast playback to specific episodes in the film [2]. Therefore, whether for professional work, hobby, or general interest, YouTube users can obtain good learning value from informal learning in YouTube [3]. Social media has been regarded as a convenient tool of online learning resources [2].

Although the application of social media in education is becoming more and more popular and all kinds of knowledge can be obtained in the media [4], the research on the use of YouTube in education mainly focuses on academic achievements and research is rarely carried out in the teaching of hand-made leather goods [5]. However, with the

Manuscript received October 1, 2020; revised January 22, 2021.

Chih-Mei Wang is with the Department of Industrial Education, National Taiwan Normal University, Taiwan (e-mail: may904wang@gmail.com).

Jian-Hong Ye is with the Department of Industrial Education and Institute for Research Excellence in Learning Sciences, National Taiwan Normal University, Taiwan (corresponding author; e-mail: kimpo30107@yahoo.com.tw).

Jhen-Ni Ye is with the Graduate Institute of Technological and Vocational Education, National Taipei University of Technology, Taiwan (e-mail: jhen13211321@gmail.com). trend of cultural and creative design, hands-on craft courses (such as leather goods, silver jewelry, etc.) have been loved by many young people [6], so more and more YouTube teaching videos for making handcraft appear. Exploring the impact of learning cognition and affective performance on the satisfaction of hand-made leather learning in the context of YouTube will help expand the understanding of the value of YouTube education. Thus, this study was based on this research topic.

The concept of computer self-efficacy helps us understand how individuals quickly adopt new tools and whether they can easily develop considerable operational skills when using these tools [7]. Computer self-efficacy has been proven to be a key factor in computer ability and computer use [8], and self-efficacy has become an important determinant of success in learning [9]. This study used participants' self-efficacy on YouTube as an independent variable for discussion.

Students' interest in learning is considered to be a very important factor in determining whether they can learn successfully or not [10]. Leutner studied various aspects of multimedia design affecting success and found that learners' personal interests played an important role in the overall learning experience of the individual [11]. Learners' interest in social media learning can be used to predict learners' satisfaction with using social media [2]. Therefore, this study used participants' learning interest in YouTube as a variable for discussion.

The learner's attitude is very important, because when learners have a good learning attitude, it will help them achieve the desired learning results [12]. Because in the online learning environment, students can freely arrange their own learning, so the learning attitudes of learners are considered to play an important role [13]. Understanding users' attitudes towards e-learning will help construct a more suitable digital learning environment for teaching and learning [14]. Therefore, this study used participants' learning attitude towards YouTube as one of the variables for discussion.

Studies have shown that the combination of film technology and teaching can promote the positive improvement of students' learning results [15], so providing high-quality learning content to learners will meet the learning needs of learners and allow them to obtain the required knowledge. Therefore, student satisfaction is used as one of the key elements for evaluating online courses [16], so that measuring student satisfaction with online learning has always been a hot topic in the academic world [17]. Therefore, this study took participants' learning satisfaction with YouTube's as a dependent variable for discussion.

The Cognitive-Affective Theory of Learning with Media (CATLM) focuses on the cognitive and affective processes in 
multimedia learning. The theory is based on the latest theoretical framework of multimedia learning and enhances recognition by considering motivation and emotional aspects [18]. Moreno's CATLM proposed that the emotional characteristics of the course can increase learners' participation, leading to deeper learning [19]. CATLM has been proven to be applicable for skills learning through YouTube [2]. Therefore, this research was based on CATLM to explore the relationship between YouTube self-efficacy, learning interest, learning attitude and learning satisfaction.

\section{A. YouTube Self-efficacy}

Self-efficacy is one of the factors that guide human activities. It affects human behavior such as personal motivation, way of thinking, and the degree and time that individuals put in effort to achieve specific goals directly or through its influence [20]. Unless people believe that their actions can produce the expected results, otherwise they have no motivation to engage in activities or persevere when encountering difficulties [21]. In the educational environment, researchers are paying more and more attention to students' the role of student's thoughts and beliefs in the learning process, and the self-efficacy in social cognitive theory is an important key variable, because it is considered to affect students' motivation and learning [22]. It is that considered self-efficacy can be used to understand students' ability, confidence and belief in completing specific tasks or activities [23], and self-efficacy is also an important concept for understanding learning and achievement [24]. At the same time, self-efficacy is also considered to be a key element of successful online learning [25]. Therefore, this research used YouTube self-efficacy to explore the learners' ability confidence or belief level in operating YouTube functions. In this research, YouTube self-efficacy is defined as the learners' confidence or belief in the ability to operate YouTube functions well when using YouTube for learning.

\section{B. Learning Interest}

Interest is a concept that has received considerable attention in education, development and social psychology in the past 20 years [26], because once people become interested in a topic, they usually seek learning opportunities both inside and outside the school [27]. Interest is conceptualized as an emotional state, which means that in the subjective learning experience of students, interest is triggered by situational factors or a state formed by the development of personal interest [28], and interest is also regarded as a personal trait, trait motivation or individual interest that is developed through repeated experience of contextual interest over a longer period of time[29]. Therefore, people are more and more interested in the research on using multimedia teaching materials to improve learners' positive emotions or motivational states to improve learning interest [30]. Thus, this study used learning interest to explore the learning interest level of learners in YouTube when they were watching the teaching of hand-made leather goods. In this research, learning interest refers to the learner's positive or negative emotional feelings when they are watching teaching of hand-made leather goods in YouTube.

\section{Learning Attitude}

Behavior attitude is defined as a person's positive or negative evaluation of the performance of a specific behavior, involving the individual's judgment on the nature of the behavior, and the evaluation of someone's willingness or unwillingness to perform the behavior [31]. There are many definitions of attitude, and the simplest definition is an individual's assessment or response to the cognition and emotion of objects, people, groups and thoughts [32]. Therefore, it is important for learners to have a good attitude, as having a good attitude will help them achieve ideal learning results [12].

Regardless how advanced or powerful the technology is, its effective implementation depends on whether users have a positive attitude towards using the technology [17]. In the context of digital learning, the learner's attitude is defined as the impression of learners participating in digital learning activities through the use of computers [33]. Cheung and Vogel proved that users' positive attitudes will cause people to be more inclined to use online learning technologies [34]. Therefore, this research used learning attitude to explore learners' attitudes towards learning hand-made leather goods through videos in YouTube. In this research, learning attitude refers to learners' positive or negative evaluation perception when learning to make hand-made leather goods via the film on YouTube.

\section{Learning Satisfaction}

Satisfaction is considered to be a measure of the quality and effectiveness of any form of teaching [35]. Taking satisfaction as a measure can give us a deep understanding of the effectiveness of teaching design [36], and student satisfaction can also be regarded as an important indicator to measure whether the learning expectation of learning is met [37]. When students experience a valuable learning process, they will be satisfied with their own learning process [38]. At the same time, user satisfaction is regarded as one of the most important indicators of success for an information system [39], and it means that students have good satisfaction when they can obtain satisfaction in online video teaching [40][41]. Therefore, this study used learning satisfaction to explore learners' degree of satisfaction of learning needs for learning hand-made leather goods through videos in YouTube. In this research, learning satisfaction refers to whether learners can meet their learning needs by learning hand-made leather goods through videos in YouTube.

\section{RESEARCH HYPOTHESES}

\section{A. Relationship between YouTube Self-efficacy and Learning Interest}

Research has shown that self-efficacy and interest were separate but interrelated dimensions [42]. Research has revealed that self-efficacy had a direct effect on interest [43]. Past studies have confirmed that improving students' sense of self-efficacy for specific tasks helped to increase players' interest in playing games in a competitive environment [44]. There is also a study based on game-based learning showing that self-efficacy and interest were positively correlated [45], and a study of Thai language learning had the same results, as 
they found that self-efficacy and interest were positively correlated [46]. A report on mathematics education pointed out that students' self-efficacy had a positive effect on interest [47]. In addition, studies have also confirmed that social media self-efficacy and learning interest were positively correlated [2]. From the above, it can be inferred that when learners have higher levels of self-efficacy, their learning interest may be higher too. The hypothesis of this research on YouTube self-efficacy and learning interest is as follows:

H1: There is a positive relation between YouTube self-efficacy and learning interest.

\section{B. Relationship between YouTube Self-efficacy and Learning Attitude}

People tend to choose activities that they think they could do, and avoid choosing activities that they do not thing they could do [22]. Therefore, self-efficacy is believed to directly affect the choice to engage in a task, and affect the time spent in making efforts and the persistence of efforts [48]. It is pointed out that positive self-efficacy can predict positive attitudes, while negative self-efficacy can predict negative attitudes [49]. Past studies have confirmed that students' sense of self-efficacy and science attitudes were positively correlated [50], and some studies have shown that students' Internet self-efficacy was highly correlated with Internet attitudes [51]. It can be inferred from the above that when learners have higher levels of self-efficacy, their learning attitudes will also be better. The hypothesis of this research on YouTube self-efficacy and learning attitude is as follows:

$\mathrm{H} 2$ : There is a positive relation between YouTube self-efficacy and learning attitude.

\section{Relationship between Learning Interest and Learning Satisfaction}

Satisfaction will be affected by positive or negative experiences in the learning process [52]. When individuals are motivated by interest, they are more likely to persist in completing tasks and be satisfied with the tasks performed [53]. In addition, if the teaching methods or content can meet the students' interests and needs, then students' learning satisfaction will also increase [54][55], and a study of game-based learning indicates that when teachers designed games-based teaching or learning process, it can arouse students' interest and increase their participation and satisfaction. That is to say, when students are motivated by interesting learning, they are more satisfied with the learning environment [56]. A research on anatomy and physiology courses has shown that students' interest in subjects was an important factor affecting satisfaction [57]. A study based on social media learning also confirmed that learning interest was positively correlated with learning satisfaction [2]. It can be inferred from the above that when learners have better learning interest, their learning satisfaction with YouTube will be better. The hypothesis of this research on learning interest and learning satisfaction is as follows:

H3: There is a positive relation between learning interest and learning satisfaction.

\section{Relationship between Learning Attitude and Learning Satisfaction}

If the learning attitude is negative or dismissive, then students have almost no opportunity to actively participate in any learning process [9]. Therefore, the discussion of learning attitudes can be used to understand students' responses to motivation [58]. Related research showed that learning satisfaction can be used to indicate learners' positive feelings or attitudes towards teaching plans [59]. A study on physical education indicated a significant positive relation between learning attitude and learning satisfaction [60]. In a technology-driven environment, learning satisfaction reflected students' positive attitudes towards learning experiences [61]. A study on mobile learning revealed that students with better attitudes showed better learning satisfaction [62], and there is also a research on the application of interactive technology in consumer behavior courses showed that students with a positive attitude towards interactive technology were more satisfied with the effect of interactive technology [63]. It can be inferred from the above that when learners have a more positive attitude towards learning, their learning satisfaction of using YouTube will be better. The hypothesis of this research on learning attitude and learning satisfaction is as follows:

$\mathrm{H} 4$ : There is a positive relation between learning attitude and learning satisfaction.

\section{RESEARCH DESIGN}

The CATLM theory believes that in a learning environment based on a combination of verbal and non-verbal information, students can practice meaningful learning by choosing, organizing and absorbing new information, and then combining existing knowledge [64], Therefore, CATLM, as a useful framework, can help deepen the understanding of the role of methods and media in teaching [65]. Accordingly, this research used the CATLM proposed by Moreno and Mayer (2007) as the theoretical framework [66] to discuss the relationship among YouTube self-efficacy, learning interest, learning attitude and learning satisfaction, as shown in Fig. 1.

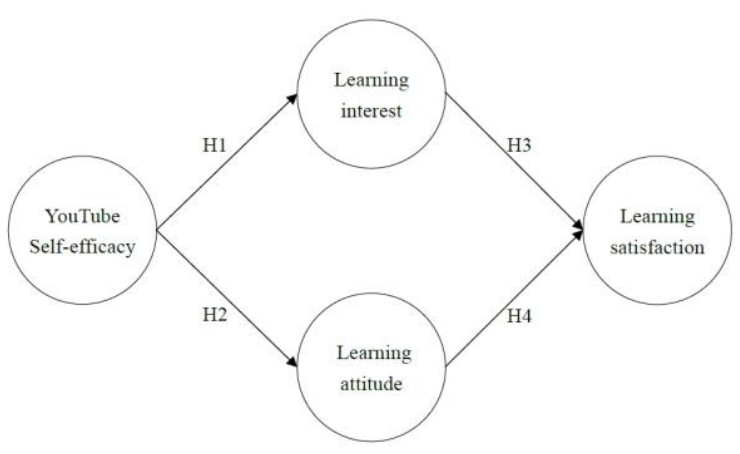

Fig. 1. Research model.

\section{A. Research Implementation}

This research used a convenient way of collecting and distributing online questionnaires using Google Forms for online questionnaire distribution. The questionnaires were collected from November 1 to December 31, 2018. The questionnaires were distributed to enthusiasts who used YouTube for hand-made leather goods self-study or training. 
The number of questionnaires collected was 258 pieces of data.

\section{B. Research Participants}

The number of participants in this study (for the number of questionnaires returned) was 258 , and a total of 51 invalid data were deleted. There were 207 valid study participants, and the effective recovery rate was $80.2 \%$, including 61 males $(29.5 \%)$, and 146 females $(70.5 \%)$; 86 participants aged under $30(41.5 \%), 45$ aged 31 to $40(21.7 \%), 47$ aged 41 to $50(22.8 \%)$, and 29 over the age of $50(14 \%) ; 71$ participants $(34.3 \%)$ mainly adopted on-line self-study for hand-made leather goods, 21 participants (10.1\%) mainly took physical courses, and 115 participants $(55.6 \%)$ equally used both learning methods.

\section{Measurement Tools}

\section{1) YouTube self-efficacy}

Self-efficacy is used to understand students' ability, confidence, and belief in completing a specific task or activity [23]. According to this definition, the YouTube self-efficacy dimensions of this research were adapted from the social media self-efficacy scale of Hong et al. [2], such as "I will use decomposition actions to simulate learning", to measure learners' perceptions of YouTube efficacy belief.

\section{2) Learning interest}

Interest is conceptualized as an emotional state, which represents the subjective learning experience of students [28]. According to this definition, this research revised the online learning interest questionnaire of Hong et al. [67], including " During the teaching process of every video, I want to continue learning and forget that the time is over" , to measure the level of interest of learners when using YouTube to learn hand-made leather goods.

\section{3) Learning attitude}

Attitude is defined as an individual's assessment or response to objects, people, groups, and thoughts on cognition and emotion [32]. According to this definition, this study compiled a learning attitude scale, including "After I watched the teaching video, I would analyze which part of my own production skills are insufficient and improve", to measure the attitude of learners when using YouTube to learn hand-made leather goods.

\section{4) Learning satisfaction}

Student satisfaction is regarded as an important indicator to measure whether students meet learning expectations [37]. According to this definition, this study modified the social media satisfaction scale of Hong et al. [2], including "I think YouTube videos can improve my understanding of leather craftsmanship", which was used to measure the satisfaction level of learners when using YouTube to learn to make leather goods by hand.

\section{RESEARCH RESULTS}

\section{A. Item Analysis}

The item analysis of this research adopted first-order confirmatory factor analysis. Related scholars suggest that the value of $\chi 2 /$ df should be less than 5; RMSEA should be less than 0.1; GFI and AGFI should be higher than .800; and the items with the factor loading (FL) value not higher than .500 should be deleted from the original questionnaire $[68,69]$, as shown in Table I. The results of the deletion are: 6 original questions for YouTube self-efficacy were reduced to 4 questions; 9 original questions of learning interest were reduced to 5 questions; 6 questions for learning attitude were reduced to 4 Questions; 5 questions about learning satisfaction were reduced to 4 questions.

TABLE I: CONFIRMATORY FACTOR ANALYSIS OF EACH CONSTRUCT

\begin{tabular}{ccccccc}
\hline \hline Index & $\chi 2$ & df. & $\chi 2 /$ df. & RMSEA & GFI & AGFI \\
\hline Threshold value & --- & --- & $<5$ & $<.1$ & $>.8$ & $>.8$ \\
\hline YouTube Self-efficacy & 2.6 & 2 & 1.3 & 0.039 & 0.994 & 0.968 \\
\hline Learning interest & 13.9 & 5 & 2.78 & 0.093 & 0.976 & 0.929 \\
\hline Learning attitude & 3 & 2 & 1.5 & 0.049 & 0.993 & 0.963 \\
\hline Learning Satisfaction & 3.5 & 2 & 1.75 & 0.060 & 0.992 & 0.959 \\
\hline \hline
\end{tabular}

This study used the external validity of the items to determine the scope of interpretation [70]. The values of all respondents for each item were divided into the first $27 \%$ and the last $27 \%$, and the $t$ test was performed; if the $t$ value was greater than $3(* * * p<0.001)$, it was considered that the external validity has reached a significant level. The $t$ value of each item in this study reached $7.235(* * * p<0.001)$, which means that all items in this study have external validity [71].

\section{B. Dimension Reliability and Validity Analysis}

Reliability: This study used Cronbach's $\alpha$ and composite reliability (CR) to test the reliability of the scale. Hair et al. suggested that Cronbach's $\alpha$ higher than 0.700 is considered acceptable standard [68], and Hair et al. suggested the standard that the CR value should exceed 0.700 [68]. The Cronbach's $\alpha$ values in this study were between 0.833 and 0.924 , and the CR values were between 0.891 and 0.934 , meeting the recommended standards, as shown in Table II.

Convergence validity: Convergence validity was tested by FL value and averaging variance extracted (AVE). Hair et al. pointed out that FL value should be higher than 0.5 .., and the item should be deleted if it is lower than this value [68]. All the items retained in this study met the standards recommended by scholars. The FL values of YouTube learning self-efficacy ranged from 0.749 to 0.885 , and the FL values of learning interest were between 0.827 to 0.938 , the FL values of learning attitude ranged from 0.775 to 0.792 , and the FL values of learning satisfaction ranged from 0.772 to 0.842 , as shown in Table II. It is recommended by Hair et al. (2011) that the AVE value must be greater than 0.500 to indicate that the dimension has convergent validity [72], and the AVE values in this research were between 0.673 and 0.741 , as shown in Table II.

Dimension discriminative validity: Awang (2015) indicated if the square root value of AVE of each dimension is greater than the Pearson relation coefficient value of other dimensions, it means that the dimension has discriminative 
validity [73]. The analysis results show that, all the dimensions of this study had discriminative validity, as shown in Table III.

TABLE II: RELIABILITY AND VALIDITY ANALYSIS

\begin{tabular}{cccccc}
\hline \hline Index & $M$ & $S D$ & $\alpha$ & CR & AVE \\
\hline Threshold & --- & --- & $>.7$ & $>.7$ & $>.5$ \\
YouTube Self-efficacy & 3.720 & 0.769 & 0.833 & 0.891 & 0.673 \\
Learning interest & 3.695 & 0.881 & 0.924 & 0.934 & 0.741 \\
Learning attitude & 3.619 & 0.794 & 0.854 & 0.898 & 0.688 \\
Learning Satisfaction & 3.655 & 0.816 & 0.854 & 0.895 & 0.680 \\
\hline \hline
\end{tabular}

TABLE III: DIMENSION DISCRIMINATION VALIDITY ANALYSIS

\begin{tabular}{lcccc}
\hline \hline \multicolumn{1}{c}{ Constructs } & 1 & 2 & 3 & 4 \\
\hline 1. YouTube Self-efficacy & $(0.820)$ & & & \\
2. Learning interest & 0.583 & $(0.861)$ & & \\
3. Learning attitude & 0.639 & 0.623 & $(0.829)$ & \\
4. Learning Satisfaction & 0.573 & 0.738 & 0.601 & $(0.825)$ \\
\hline \hline
\end{tabular}

\section{Path Analysis}

The research model verification results showed that YouTube self-efficacy was positively related to learning interest $(\beta=0.592 * * *, t=9.658)$, and YouTube self-efficacy was positively related to learning attitude $\left(\beta=0.623^{* * *}, t=\right.$ 10.992), learning interest had a positive relation with learning satisfaction $(\beta=0.394 * * *, t=4.765)$, and learning attitude had a positive relation with learning satisfaction $(\beta=$ $0.422 * * *, t=5.352$ ), as shown in Fig. 2.

In addition, the explanatory power of YouTube self-efficacy on learning interest was $35 \%, f 2$ was 0.583 ; the explanatory power of YouTube self-efficacy on learning attitude was $38.8 \%, f 2$ was 0.634 ; the explanatory power of learning interest and learning attitude on learning satisfaction was 64\%, $f 2$ was 1.793, as shown in Fig. 2.

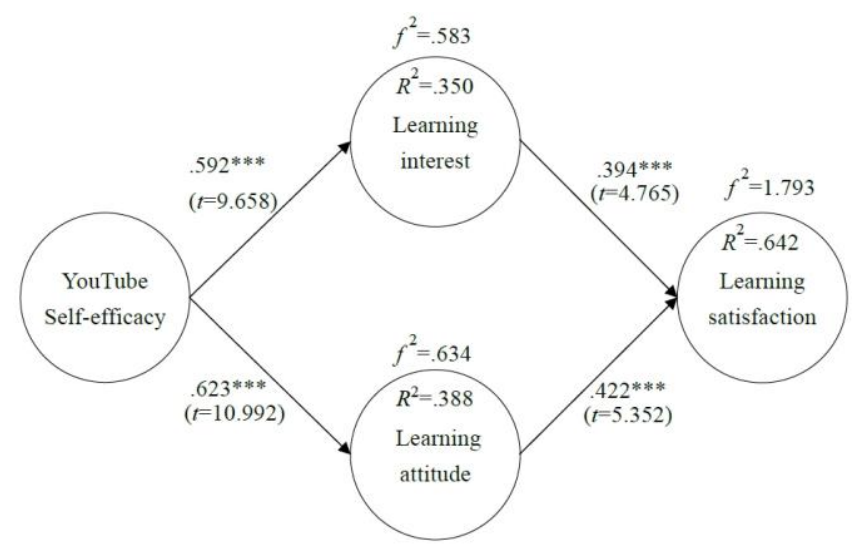

$p^{* * *}<.001$

Fig. 2. Research model verification.

\section{DISCUSSION}

Understanding people's computer self-efficacy beliefs can help to explain whether they can easily develop considerable operational skills when using these tools [7], and the analysis of this research showed that participants had positive YouTube self-efficacy beliefs $(M=3.720, S D=0.769)$; interest was conceptualized as an emotional state, representing the subjective learning experience of students[28]. The analysis of this research showed that participants had a positive perception of learning interest $(M$ $=3.695, S D=0.881)$. A good learning attitude is believed to help students achieve ideal learning outcomes [12]. The analysis of this research showed that participants had positive learning attitude perception $(M=3.619, S D=0.794)$; students' satisfaction is regarded as an indicator to measure whether the learning expectation of learning is met [37]. The analysis of this research showed that participants had a positive perception of learning satisfaction $(M=3.655, S D=$ $0.816)$.

\section{A. YouTube Self-efficacy was Positively Related to Learning Interest}

Rottinghaus et al. stated that self-efficacy and interest were mutually independent but interrelated dimensions, while the study of Chiang et al. showed that self-efficacy had a direct effect on interest [42]. In addition, Hong et al. further found that improving students' sense of self-efficacy for specific tasks will help increase players' interest in playing games in a competitive environment [44]. Hong and Chan's study on game-based learning indicated that self-efficacy and interest were positively correlated [45]. The Thai language learning study conducted by Watthanapas et al. reported the same result [46]. Watthanapas et al. found that self-efficacy and interest were positively correlated, Lai pointed out that students' self-efficacy had a positive effect on interest in mathematics education [47]. In addition, Hong et al. confirmed that the self-efficacy of social media was positively correlated with learning interest [2]. It can be seen from the above that when learners have a higher level of self-efficacy, their learning interest may also be higher. The results of this research showed that YouTube self-efficacy and learning interest were positively correlated.

\section{B. YouTube Self-efficacy was Positively Related to Learning Attitude}

Van Dinther et al. pointed out that people tend to choose activities that they think are capable, and avoid choosing activities that they are not capable of [22]. Therefore, Huang and Liaw pointed out that self-efficacy based on ability belief perception is believed to directly affect the choice to engage in a task, the time spent in making efforts and the persistence of efforts [48]. Akin and Kurbanoglu confirmed that positive self-efficacy can predict positive attitudes and negative self-efficacy can predict negative attitudes [49]. In addition, Liu et al. suggested that students' sense of self-efficacy was positively correlated with scientific attitudes [50]. Wu and Tsai noted that students' Internet self-efficacy was highly correlated with Internet attitudes [51]. It can be seen from the above that when learners have higher levels of self-efficacy, their learning attitudes will be better. The results of this research showed that YouTube self-efficacy and learning attitude were positively correlated.

\section{Learning Interest was Positively Related to h Learning Satisfaction}

Chen et al. suggested that satisfaction will be affected by positive or negative experiences in the learning process [52]. Sansone et al. pointed out that when individuals were motivated by interest, they were more likely to persist in completing tasks and be satisfied with the tasks and activities performed [53]. In addition, Abdous and Yen (2010), Safari et al. found that when the teaching method or content can 
meet the students' interests and needs, then students' learning satisfaction will also increase [54]. Kangas et al. mentioned that when students were motivated by interesting learning, they were more satisfied with the learning environment [56]. In addition, Eagleton indicated that students' interest in subjects was an important factor affecting satisfaction [57]. Hong et al. based on social media learning, also confirmed that learning interest was positively correlated with learning satisfaction [2]. It can be seen from the above that when learners have a better interest in learning, their learning satisfaction with YouTube will be better too. The results of this research showed that learning interest and learning satisfaction had a positive relation.

\section{Learning Attitude Positively Correlated with Learning Satisfaction}

Prior et al. indicated that when a student's learning attitude is negative or dismissive, then the student has almost no desire to actively participate in any learning process [9]. Love et al. suggested that exploring learning attitude can be used to understand students' responses to motivation [58]. Kong and Yan (2014) pointed out that learning satisfaction can be used to indicate learners' positive feelings or attitudes towards the teaching plan [59]. Lin et al. found a significant positive relation between learning attitude and learning satisfaction [60]. In addition, $\mathrm{Li}$ 's research indicated that students with better attitudes will show better learning satisfaction [62]. Elia et al. noted that in a technology-driven environment, learning satisfaction reflected students' positive attitudes towards learning experience [61]. Eastman et al. proved that students who held a more positive attitude toward interactive technology were more satisfied with the effects of interactive technology [63]. From the above, it can be seen that when learners have a more positive learning attitude, they will be more satisfied with the use of YouTube in learning. The results of this research showed that there was a positive relation between learning attitude and learning satisfaction.

\section{CONCLUSION AND SUGGESTIONS}

\section{A. Research Conclusion and Suggestions}

The video courses on YouTube provide information and instructions for learning information, demonstrating the process or acquiring new skills. Learners can learn by watching and trying to copy the instruction steps in the video [74], so YouTube may enhance its educational function for step-by-step learning and guidance [1]. Therefore, in the era of the Internet, YouTube has become a highly popular learning tool. In the perspective of CATLM [65], formal or informal learning model through YouTube can be regarded as a meaningful learning method. According to this, on the basis of CATLM, the belief-affection-cognitive model was used to construct the hypothetical model of this research and 4 research hypotheses were put forward. The research results showed that: 1) YouTube self-efficacy was positively related to learning interest; 2) YouTube self-efficacy was positively related to learning attitude; 3) Learning attitude was positively related to $\mathrm{h}$ learning satisfaction; 4) Learning interest was positively related to learning satisfaction. It can be seen from the research results that YouTube can bring a meaningful learning journey for learners. Therefore, this research suggested that professional or amateur teachers can design multimedia teaching content based on learning theory to provide learners with good and appropriate learning materials to help them learn skills online.

\section{B. Limitations and Future Studies}

This is a confirmatory study based on the structural equation model, aiming to explore the path relationship between the dimensions. Therefore, the analysis of individual differences was not the focus of this study. However, there have been many empirical studies in the past that have found significant gender differences in efficacy [25]. In this study, whether YouTube self-efficacy has gender differences was not explored, so it is recommended that follow-up research can investigate whether there are differences in beliefs and perceptions of YouTube self-efficacy for different genders. In addition, although there are not many papers on gender differences in e-learning, most of them pointed out that male students are usually more willing to use computers for learning than female students [75]. However, the comparison of individual differences was not discussed in this study. Follow-up research is also recommended to explore whether there are differences in the perception of learning interest, learning attitude and learning satisfaction among different genders in the environment of learning on YouTube.

\section{CONFLICT OF INTEREST}

The authors declare no conflict of interest.

\section{INTEREST AND AUTHOR CONTRIBUTION}

First and second author conducted the research and collected data; first and third author analyzed the data; all authors wrote the paper; all authors had approved the version.

\section{ACKNOWLEDGEMENT}

This work was financially supported by the "Institute for Research Excellence in Learning Sciences" and "Chinese Language and Technology Center" of National Taiwan Normal University (NTNU) from The Featured Areas Research Center Program within the framework of the Higher Education Sprout Project by the Ministry of Education (MOE) in Taiwan.

\section{REFERENCES}

[1] D. Y. Lee and M. R. Lehto, "User acceptance of YouTube for procedural learning: An extension of the technology acceptance model," Computers \& Education, vol. 61, pp. 193-208, 2013.

[2] J. C. Hong, M. Y. Hwang, E. Szeto, C. R. Tsai, Y. C. Kuo, and W. Y. Hsu, "Internet cognitive failure relevant to self-efficacy, learning interest, and satisfaction with social media learning," Computers in Human Behavior, vol. 55, pp. 214-222, 2016.

[3] J. E. Klobas, T. J. McGill, S. Moghavvemi, and T. Paramanathan, "Problematic and extensive YouTube use: First hand reports," Online Information Review, vol. 43, no. 2, pp. 265-282, 2019.

[4] J. C. Hong, M. L. Chen, and J. H. Ye, “Acceptance of YouTube applied to dance learning," International Journal of Information and Education Technology, vol. 10, no. 1, pp. 7-13, 2020.

[5] A. DeWitt and N. Dorothy, "The potential of Youtube for teaching and learning in the performing arts," Procedia - Social and Behavioral Sciences, vol. 103, pp. 1118-1126, 2013. 
[6] J. H. Ye, C. M. Wang, J. Y. Fan, Y. F. Wu, and J. N. Ye, "The association of hands-on making attitude, course interest, and continuous intention to participate in courses related to leather goods," Taiwan Textile Research Journal, vol. 30, no. 2, pp. 64-72, 2020.

[7] G. Torkzadeh and T. P. van Dyke, "Effects of training on Internet self-efficacy and computer user attitudes," Computers in Human Behavior, vol. 18, no. 5, pp. 479-494, 2002.

[8] B. Hasan, "The influence of specific computer experiences on computer self-efficacy beliefs," Computers in Human Behavior, vol. 19, no. 4, pp. 443-450, 2003.

[9] D. D. Prior, J. Mazanov, D. Meacheam, G. Heaslip, and J. Hanson, "Attitude, digital literacy and self efficacy: Flow-on effects for online learning behavior," The Internet and Higher Education, vol. 29, pp. 91-97, 2016.

[10] N. J. Navimipour and B. Zareie, "A model for assessing the impact of e-learning systems on employees' satisfaction," Computers in Human Behavior, vol. 53, pp. 475-485, 2015.

[11] D. Leutner, "Motivation and emotion as mediators in multimedia learning," Learning and Instruction, vol. 29, pp. 174-175, 2014.

[12] M. C. Chong, K. Francis, S. Cooper, K. L. Abdullah, N. T. T. Hmwe, and S. Sohod, "Access to, interest in and attitude toward e-learning for continuous education among Malaysian nurses," Nurse Education Today, vol. 36, pp. 370-374, 2016.

[13] N. Dahalan, H. Hassan, and H. Atan, "Student engagement in online learning: Learners attitude toward E-Mentoring," Procedia-Social and Behavioral Sciences, vol. 67, pp. 464-475, 2012.

[14] S. S. Liaw, H. M. Huang, and G. D. Chen, "Surveying instructor and learner attitudes toward e-learning," Computers \& Education, vol. 49, no. 4 , pp. 1066-1080, 2007

[15] T. Jones and K. Cuthrell, "YouTube: Educational potentials and pitfalls," Computers in the Schools, vol. 28, no. 1, pp. 75-85, 2011.

[16] E. Alqurashi, "Predicting student satisfaction and perceived learning within online learning environments," Distance Education, vol. 40, no. 1, pp. 133-148, 2019

[17] M. B. Horzum, "Interaction, structure, social presence, and satisfaction in online learning," Eurasia Journal of Mathematics, Science and Technology Education, vol. 11, no. 3, pp. 505-512, 2015.

[18] B. Park, J. L. Plass, and R. Brünken, "Cognitive and affective processes in multimedia learning," Learning and Instruction, vol. 29, pp. $125-127,2014$

[19] R. Moreno, "Instructional technology: Promise and pitfalls," in L. M. PytlikZillig, M. Bodvarsson, and R. Brunning, eds., Technology-Based Education, Greenwich, CT: Information Age Publishing, 2005, pp. 1-2.

[20] R. Latikka, T. Turja, and A. Oksanen, "Self-efficacy and acceptance of robots," Computers in Human Behavior, vol. 93, pp. 157-163, 2019.

[21] A. Bandura, "Self-efficacy," in I. B. Weiner, and W. E. Craighead, eds., The Corsini Encyclopedia of Psychology, Hoboken, NJ: John Wiley \& Sons, 2010, pp. 1-3.

[22] M. Dinther, F. Dochy, and M. Segers, "Factors affecting students' self-efficacy in higher education," Educational Research Review, vol. 6, no. 2, pp. 95-108, 2011.

[23] A. Bandura, "Social foundations of thought and action: A social cognitive theory," Englewood Cliffs, NJ: Prentice-Hall, 1986.

[24] O. E. Hatlevik, I. Throndsen, M. Loi, and G. B. Gudmundsdottir, "Students' ICT self-efficacy and computer and information literacy: Determinants and relationships," Computers \& Education, vol. 118, pp. 107-119, 2018.

[25] D. Shen, M. H. Cho, C. L. Tsai, and R. Marra, "Unpacking online learning experiences: Online learning self-efficacy and learning satisfaction," The Internet and Higher Education, vol. 19, pp. 10-17, 2013.

[26] S. Hidi and M. Ainley, "Interest and self-regulation: Relationships between two variables that influence learning," in D. H. Schunk \& B. J. Zimmerman, eds., Motivation and Self-regulated learning: Theory, Research, and Applications, Mahwah, NJ: Lawrence Erlbaum Associates Publishers, 2008, pp. 77-109.

[27] B. Barron, "Interest and self-sustained learning as catalysts of development: A learning ecology perspective," Human Development, vol. 49, no. 4, pp. 193-224, 2006.

[28] M. Ainley, "Connecting with learning: Motivation, affect and cognition in interest processes," Educational Psychology Review, vol. 18 , no. 4, pp. 391-405, 2006.

[29] T. B. Tin, "Stimulating student interest in language learning," London, UK: Palgrave Macmillan, 2016.

[30] C. Brom, F. Děchtěrenko, N. Frollová, T. Stárková, E. Bromová, and S. K. D'Mello, "Enjoyment or involvement? Affective-motivational mediation during learning from a complex computerized simulation," Computers \& Education, vol. 114, pp. 236-254, 2017.
[31] I. Ajzen and M. Fishbein, Understanding Attitudes and Predicting Social Behavior, Englewood Cliffs, NJ: Prentice Hall, 1980.

[32] G. Bohner and N. Dickel, "Attitudes and attitude change," Annual Review of Psychology, vol. 62, pp. 391-417, 2011.

[33] N. Nurhayani, R. Rosnawati, and T. Amimah, "Optimization of guided discovery learning models to increase students' interest in mathematics," Infinity Journal, vol. 9, no. 1, pp. 69-80, 2020.

[34] R. Cheung and D. Vogel, "Predicting user acceptance of collaborative technologies: An extension of the technology acceptance model for e-learning," Computers \& Education, vol. 63, pp. 160-175, 2013.

[35] J. Wu, R. D. Tennyson, and T. L. Hsia, "A study of student satisfaction in a blended e-learning system environment," Computer \& Education, vol. 55, pp. 155-164, 2010.

[36] G. R. Bradford, "A relationship study of student satisfaction with learning online and cognitive load: Initial results," The Internet and Higher Education, vol. 14, no. 4, pp. 217-226, 2011.

[37] P. Garnjost and L. Lawter, "Undergraduates' satisfaction and perceptions of learning outcomes across teacher-and learner-focused pedagogies," The International Journal of Management Education, vol. 17 , no. 2, pp. 267-275, 2019.

[38] M. R. Smith, L. Grealish, and S. Henderson, "Shaping a valued learning journey: Student satisfaction with learning in undergraduate nursing programs, a grounded theory study," Nurse Education Today, vol. 64, pp. 175-179, 2018

[39] W. H. Delone and E. R. McLean, "The DeLone and McLean model of information systems success: A ten-year update," Journal of Management Information Systems, vol. 19, no. 4, pp. 9-30, 2003.

[40] M. Torres-Ramírez, B. García-Domingo, J. Aguilera, and J. Casa, "Video-sharing educational tool applied to the teaching in renewable energy subjects," Computers \& Education, vol. 73, pp. 160-177, 2014

[41] T. O. Tugrul, "Student perceptions of an educational technology tool: Video recordings of project presentations," Procedia-Social and Behavioral Sciences, vol. 64, pp. 133-140, 2012.

[42] P. J. Rottinghaus, L. M. Larson, and F. H. Borgen, "The relation of self-efficacy and interests: A meta-analysis of 60 samples," Journal of Vocational Behavior, vol. 62, no. 2, pp. 221-236, 2003.

[43] C. F. Chiang, Y. C. Lai, and F. M. Chang, "The relationships among social support, self-efficacy, outcome expectations, interest, and career intention of early childhood care and education department students," Chinese Journal of Guidance and Counseling, vol. 45, pp. 123-147, 2016.

[44] J. C. Hong, M. Y. Hwang, K. H. Tai, and P. C. Lin, "Self-efficacy relevant to competitive anxiety and gameplay interest in the one-on-one competition setting," Educational Technology Research and Development, vol. 63, no. 5, pp. 791-807, 2015.

[45] J. C. Hong and C. H. Chan, "Game performance in covariation reasoning: The correlates between gameplay self-efficacy, and metacognition reflected gameplay anxiety and gameplay interest," Journal of Research in Education Sciences, vol. 63, no. 3, pp. 131-162, 2018.

[46] N. Watthanapas, Y. W. Hao, and M. Y. Hwang, "Exploring learning effect on innovative Thai spelling system: Correlates among learning self-efficacy, learning interest, learning anxiety, and learning achievement," Journal of Research in Education Sciences, vol. 6, no. 3 , pp. 1-29, 2019

[47] Y. C. Lai, "The effects of teacher support, math self-efficacy, and math interest on career intention," Chinese Journal of Guidance and Counseling, vol. 28, pp. 1-27, 2010.

[48] H. M. Huang and S. S. Liaw, "Exploring users' attitudes and intentions toward the web as a survey tool," Computers in Human Behavior, vol. 21 , no. 5, pp. 729-743, 2005

[49] A. Akin and I. N. Kurbanoglu, "The relationships between math anxiety, math attitudes, and self-efficacy: A structural equation model," Studia Psychologica, vol. 53, no. 3, pp. 263-273, 2011

[50] M. Liu, Y. Cho, and D. Schallert, "Middle school students' self-efficacy, attitudes, and achievement in a computer-enhanced problem-based learning environment," Journal of Interactive Learning Research, vol. 17, no. 3, pp. 225-242, 2006.

[51] Y. T. Wu and C. C. Tsai, "University students' Internet attitudes and internet self-efficacy: A study at three universities in Taiwan," Cyberpsychology \& Behavior, vol. 9, no. 4, pp. 441-450, 2006.

[52] N. S. Chen, K. M. Lin, and Kinshuk, "Analysing users' satisfaction with e-learning using a negative critical incidents approach," Innovations in Education and Teaching International, vol. 45, no. 2, pp. $115-126,2008$

[53] C. Sansone, J. L. Smith, D. B. Thoman, and A. MacNamara, "Regulating interest when learning online: Potential motivation and 
performance trade-offs," The Internet and Higher Education, vol. 15, no. 3, pp. 141-149, 2012.

[54] M. H. Abdous and C. J. Yen, "A predictive study of learner satisfaction and outcomes in face-to-face, satellite broadcast, and live video-streaming learning environments," The Internet and Higher Education, vol. 13, no. 4, pp. 248-257, 2010.

[55] F. Safari, N. Safari, and A. Hasanzadeh, "The adoption of software-as-a-service (SaaS): Ranking the determinants," Journal of Enterprise Information Management, vol. 28, no. 3, pp. 400-422, 2015.

[56] M. Kangas, P. Siklander, J. Randolph, and H. Ruokamo, "Teachers' engagement and students' satisfaction with a playful learning environment," Teaching and Teacher Education, vol. 63, pp. 274-284, 2017.

[57] S. Eagleton, "An exploration of the factors that contribute to learning satisfaction of first-year anatomy and physiology students," Advances in Physiology Education, vol. 39, no. 3, pp. 158-166, 2015.

[58] E. G. Love, D. W. Love, and G. B. Northcraft, "Is the end in sight? Student regulation of in-class and extra-credit effort in response to performance feedback," Academy of Management Learning \& Education, vol. 9, no. 1, pp. 81-97, 2010.

[59] H. Kong and Q. Yan, "The relationship between learning satisfaction and career competencies," International Journal of Hospitality Management, vol. 41, pp. 133-139, 2014.

[60] P. Y. Lin, C. F. Huang, and J. Lee, "The study on the learning attitudes and satisfaction for students during a squash course," Journal of Health and Care Science, vol. 1, no. 1, pp. 145-161, 2012.

[61] G. Elia, G. Solazzo, G. Lorenzo, and G. Passiante, “Assessing learners' satisfaction in collaborative online courses through a big data approach," Computers in Human Behavior, vol. 92, pp. 589-599, 2019

[62] Y. Li, "Effects of the application of mobile learning to criminal law education on learning attitude and learning satisfaction," EURASIA Journal of Mathematics, Science and Technology Education, vol. 14, pp. 7, pp. 3355-3362, 2018.

[63] J. K. Eastman, R. Iyer, and K. L. Eastman, "Business students' perceptions, attitudes, and satisfaction with interactive technology: An exploratory study," Journal of Education for Business, vol. 86, no. 1, pp. 36-43, 2011.

[64] R. Moreno and R. Mayer, "Interactive multimodal learning environments," Educational Psychology Review, vol. 19, no. 3, pp. 309-326, 2007.

[65] R. Moreno, "Does the modality principle hold for different media? A test of the method-affects-learning hypothesis," Journal of Computer Assisted Learning, vol. 22, no. 3, pp. 149-158, 2006.

[66] R. E. Mayer, Multimedia Learning, New York, NY: Cambridge University Press, 2007.

[67] J. C. Hong, M. Y. Hwang, M. C. Liu, H. Y. Ho, and Y. L. Chen, "Using a "prediction-observation-explanation" inquiry model to enhance student interest and intention to continue science learning predicted by their Internet cognitive failure," Computers \& Education, vol. 72, pp. 110-120, 2014.

[68] J. F. Hair, W. C. Black, B. J. Babin, and R. E. Anderson, Multivariate Data Analysis, Upper Saddle River, NJ: Pearson Prentice Hall, 2010.

[69] D. A. Kenny, B. Kaniskan, and D. B. McCoach, "The performance of RMSEA in models with small degrees of freedom," Sociological Methods \& Research, vol. 44, no. 3, pp. 486-507, 2015.
[70] M. K. Cor, "Trust me, it is valid: Research validity in pharmacy education research," Currents in Pharmacy Teaching and Learning, vol. 8, no. 3, pp. 391-400, 2016.

[71] S. B. Green and N. Salkind, Using SPSS for Windows and Macintosh: Analyzing and Understanding Data, Englewood Cliffs, NJ: Prentice-Hall, 2004.

[72] J. F. Hair, C. M. Ringle, and M. Sarstedt, "PLS-SEM: Indeed a silver bullet," Journal of Marketing Theory and Practice, vol. 19, no. 2, pp. 139-152, 2011.

[73] Z. Awang, "SEM made simple, a gentle approach to learning structural equation modeling," Selangor, MY: MPWS Rich Publication Sdn. Bhd, 2015.

[74] P. G. Lange, "Informal learning on YouTube," in R. Hobbs, and P. Mihailidis, eds., The International Encyclopedia of Media Literacy, Hoboken, NJ: John Wiley \& Sons, 2019, pp. 1-11.

[75] F. González-Gómez, J. Guardiola, Ó. M. Rodríguez, and M. Á. M. Alonso, "Gender differences in e-learning satisfaction," Computers \& Education, vol. 58, no. 1, pp. 283-290, 2012.

Copyright $($ C 2021 by the authors. This is an open access article distributed under the Creative Commons Attribution License which permits unrestricted use, distribution, and reproduction in any medium, provided the original work is properly cited (CC BY 4.0).

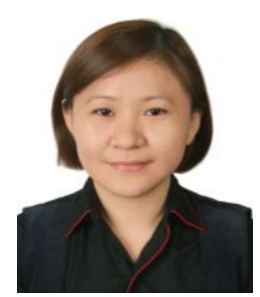

Chih-Mei Wang is a PhD student at the Department of Industrial Education, National Taiwan Norma University. She serves as a President at the Namchow foods consulting firm, Namchow Group.

Ms. Wang's main research interests include digital learning, Restaurant Management and vocational education.

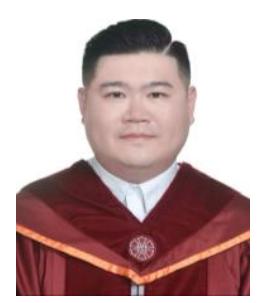

Jian-Hong Ye is a postdoctoral fellow at the Department of Industrial Education, National Taiwan Normal University. He serves as a member at the Institute for Research Excellence in Learning Sciences and Chinese Language and Technology Center, National Taiwan Normal University.

Dr. Ye's main research interests include digital learning, game-based learning, and design education.

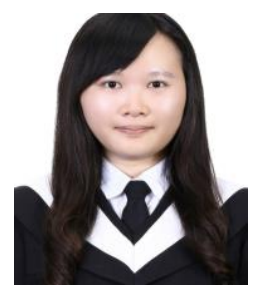

Jhen-Ni Ye is a PhD student at the Graduate Institute of Technological \& Vocational Education, National Taipei University of Technology. She serves as a research assistant at the Graduate Institute of Technological \& Vocational Education, National Taipei University of Technology.

Miss Ye's main research interests include digital learning, game-based learning, and vocational

education. 